\title{
Advances in Materials
}

\section{As-cast Microstructures and Mechanical Properties of Mg-5Y-2Nd-xSm-0.5Zr ( $x=0,1,3,5)$ Magnesium Alloys}

\author{
Gui Yunwei $^{1}$, Li Quanan ${ }^{1,2}$, Chen Xiaoya ${ }^{1}$, Li Zhitao ${ }^{1}$ \\ ${ }^{1}$ School of Materials Science and Engineering, Henan University of Science and Technology, Luoyang, China \\ ${ }^{2}$ Collaborative Innovation Center of Nonferrous Metals, Luoyang, China
}

Email address:

guiyunwei1@163.com (Gui Yunwei), liquanan2016@163.com (Li Quanan), chenxiaoya2010@163.com (Chen Xiaoya), csx199595@163.com (Li Zhitao)

\section{To cite this article:}

Gui Yunwei, Li Quanan, Chen Xiaoya, Li Zhitao. As-cast Microstructures and Mechanical Properties of Mg-5Y-2Nd-xSm-0.5Zr (x=0, 1, 3, 5) Magnesium Alloys. Advances in Materials. Vol. 7, No. 2, 2018, pp. 58-63. doi: 10.11648/j.am.20180702.17

Received: June 22, 2018; Accepted: July 30, 2018; Published: August 13, 2018

\begin{abstract}
The microstructures and mechanical properties of the as-cast Mg-5Y-2Nd-xSm-0.5Zr $(\mathrm{x}=0,1,3,5)$ alloys have been investigated by optical microscope (OM), scanning electron microscopy (SEM), energy dispersive spectrometer (EDS) analysis, transmission electron microscopy (TEM), X-ray diffraction (XRD) and mechanical tensile test. The results show that all the as-cast alloys are mainly composed of $\alpha-\mathrm{Mg}, \mathrm{Mg}_{24} \mathrm{Y}_{5}$ and $\mathrm{Mg}_{41} \mathrm{Nd}_{5}$. After adding $\mathrm{Sm}$, the alloy has a new phase of $\mathrm{Mg}_{41} \mathrm{Sm}_{5}$. Furthermore, grain gets refinement, the second phases gradually increase and the morphology of second phases transforms to continuous network distribution. In addition, the mechanical properties of the as-cast alloys vary with Sm content. With the increase of Sm, the ultimate tensile strength, yield strength and hardness of the alloy increase firstly and then decrease, and the elongation decreases. When the amount of $\mathrm{Sm}$ is $3 \%$, the alloy has the best mechanical properties, and the ultimate tensile strength, yield strength, hardness and elongation are 245.9 MPa, 207.6 MPa, HV85.9 and 5.88\%, respectively. The Mg-5Y-2Nd-0.5Zr alloy to which Sm is not added has a mixed fracture characteristic of ductile fracture and local cleavage fracture. In comparison, when the $\mathrm{Sm}$ is $3 \%$, the tear surface of the fracture surface is fine and uniform, and there is no obvious secondary crack and a large dissociation surface, indicating that the fracture energy absorbs more energy, so it shows a high fracture. Strength and high elongation.
\end{abstract}

Keywords: Mg-Y-Nd Alloy, Sm, Microstructures, Mechanical Properties

\section{Introduction}

Magnesium and its alloys have low density, high specific strength, specific rigidity, good recyclability, good casting properties, good welding performance, etc., and are increasingly used in aerospace, automotive, $3 \mathrm{C}$ products and medical equipment, etc. In many fields [1-4], known as "the 21 st century green engineering materials." However, the disadvantage of relatively poor heat resistance of ordinary magnesium alloys greatly limits the development and application of magnesium alloys [3-6]. Therefore, the development of heat-resistant magnesium alloys with better performance has become an important research direction in the application of magnesium alloys [1-7].

The common magnesium alloy strengthening method is mainly to strengthen the alloy by adding alloying elements such as $\mathrm{Sr}, \mathrm{Si}, \mathrm{Ca}$, and $\mathrm{RE}$, among which the rare earth element has a more prominent strengthening effect in magnesium alloys due to its similar crystal structure to that of magnesium. It has been found that adding two or more rare earth elements of different light and heavy rare earth components to a magnesium alloy can increase the content of the second phase, thereby exerting a better strengthening effect. According to this principle, a series of rare earth heat-resistant magnesium alloys have been developed at home and abroad [4-8]. Among them, WE-based (Mg-Y-Nd) magnesium alloys have been widely used as the most successful commercial heat-resistant magnesium alloys. Studies have shown that the main strengthening mechanism of this series of alloys is the second phase strengthening of $\mathrm{Y}$ and $\mathrm{Nd}$ elements [7-11]. Compared with $\mathrm{Nd}, \mathrm{Sm}$ shows higher maximum solubility and second phase strengthening effect in magnesium alloys, and the price is cheaper [6-12]. 
Li Quanan et al. studied the microstructure and properties of Mg-10Y-0.5Sm alloy [13]. The results show that the addition of $0.5 \mathrm{wt} \% \mathrm{Sm}$ can not only promote the fine dispersion of $\mathrm{Mg}_{24} \mathrm{Y}_{5}$ phase, but also improve their morphology and distribution. The thermal stability of the $\mathrm{Mg}_{24} \mathrm{Y}_{5}$ phase is increased; at the same time, the addition of Sm significantly increases the tensile strength of the Mg-10Y alloy. Based on this, the research and development of the more mature commercial WE series magnesium alloy as the base alloy, the use of Sm elements with higher solid solubility to replace part of the $\mathrm{Nd}$ elements in the $\mathrm{Mg}-\mathrm{Y}-\mathrm{Nd}$ alloy, aimed at reducing costs while developing A more excellent heat-resistant magnesium alloy, and systematically explore the strengthening effect and mechanism of Sm element in multi-component rare earth magnesium alloy [5-16]. In this paper, Mg-5Y-2Nd-xSm-0.5Zr ( $\mathrm{x}=0,1,3,5)$ series alloys were prepared by mixed gas protection, and $\mathrm{Mg}-5 \mathrm{Y}-2 \mathrm{Nd}-$ was studied by microscopic analysis, mechanical properties testing and analysis. The microstructure and mechanical properties of Mg-5Y-2Nd-xSm-0.5Zr series alloys.

\section{Experimental Procedures}

The raw materials used to prepare the experimental alloys were: intermediates of pure magnesium $(\geq 99.98 \%), \mathrm{Mg}-\mathrm{Y}$ (30\%), Mg-Nd (30\%), Mg-Sm (30\%), and Mg-Zr (30\%). alloy. The actual composition of the alloy obtained by the full spectrum direct reading inductively coupled plasma emission spectrometer (ICP) was as shown in Table 1.

Table 1. Chemical composition of the tested alloys (mass\%).

\begin{tabular}{lllll}
\hline Alloys & Y & Nd & Sm & Zr \\
\hline Mg-5Y-2Nd-0.5Zr & 5.17 & 194 & 0 & 0.45 \\
Mg-5Y-2Nd-1Sm-0.5Zr & 5.15 & 1.96 & 1.10 & 0.61 \\
Mg-5Y-2Nd-3Sm-0.5Zr & 5.24 & 2.01 & 3.04 & 0.49 \\
Mg-5Y-2Nd-5Sm-0.5Zr & 5.31 & 2.10 & 4.67 & Bal. \\
\hline
\end{tabular}

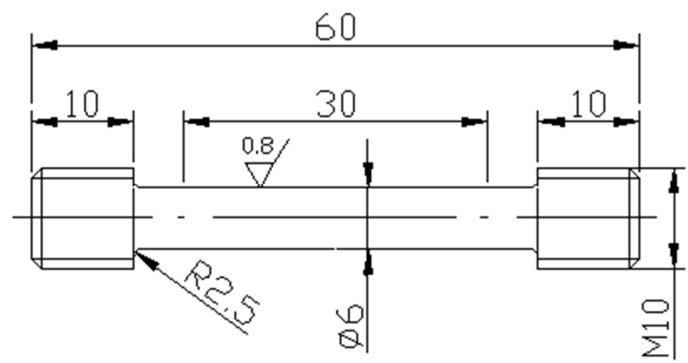

Figure 1. Shape and size of cylindrical tensile specimen (unit: mm).

Before smelting, it is necessary to put all the prepared raw materials into a drying oven and dry it for about $1 \mathrm{~h}$. The molds and the sprue cups are preheated to $200^{\circ} \mathrm{C}$. in the furnace. The smelting of the alloy is carried out in an electromagnetic induction furnace. During the smelting process, a mixture of $\mathrm{CO}_{2}$ and $\mathrm{SF}_{6}$ having a volume ratio of 99:1 continues to act as a protective atmosphere. When the temperature was heated to $700^{\circ} \mathrm{C}$, the pure magnesium ingot was placed first, and after completely melting, the $\mathrm{Mg}-\mathrm{Y}$, $\mathrm{Mg}-\mathrm{Nd}, \mathrm{Mg}-\mathrm{Sm}$, and $\mathrm{Mg}-\mathrm{Zr}$ master alloys were sequentially added. After the alloy is melted, it is left to stand by stirring and kept at a temperature of $730^{\circ} \mathrm{C}$. for 10 minutes. When the molten metal is cooled down to $700^{\circ} \mathrm{C}-710^{\circ} \mathrm{C}$, it is cast into a preheated metal mold.

The microstructure of the alloy was analyzed using an Olympus optical microscope, an X'pertmpdpro type X-ray diffractometer, a JSM-5610 LV scanning electron microscope (SEM) and a transmission electron microscope (TEM) with an energy spectrum device (EDS). Phase and composition were observed and analyzed. The hardness value of the alloy was measured by an Akashi (MVK-E) hardness tester with a load of $250 \mathrm{~g}$ and a holding time of $10 \mathrm{~s}$. Tensile tests were performed on a Shimadzu AG-I $250 \mathrm{KN}$ precision universal testing machine with a tensile rate of $1 \mathrm{~mm} / \mathrm{min}$. The tensile test specimens were shaped and dimensioned as shown in Figure 1.

\section{Results and Discussion}

\subsection{Microstructure}

The metallographic microstructures of the four alloys in the as-cast state are shown in Figure 2. From Figure 2 (a), it can be seen that the $\mathrm{Mg}-5 \mathrm{Y}-2 \mathrm{Nd}-0.5 \mathrm{Zr}$ alloy is mainly composed of an $\alpha-\mathrm{Mg}$ matrix and a small amount of black second phases distributed inside the grains. After observing Figure 2 (b)-(d), after the addition of Sm element, a long second phase begins to appear in the alloy, which is formed first at the trigeminal boundary and grows along the grain boundary as the Sm content increases. Obviously increased. When the Sm content is $5 \%$, the second phase in the alloy is substantially continuous in the grain boundary. The grain size of four kinds of alloy samples was measured, and the average grain size gradually decreased. This shows that the addition of appropriate amount of Sm element has a good refining effect on the as-cast alloy grains.

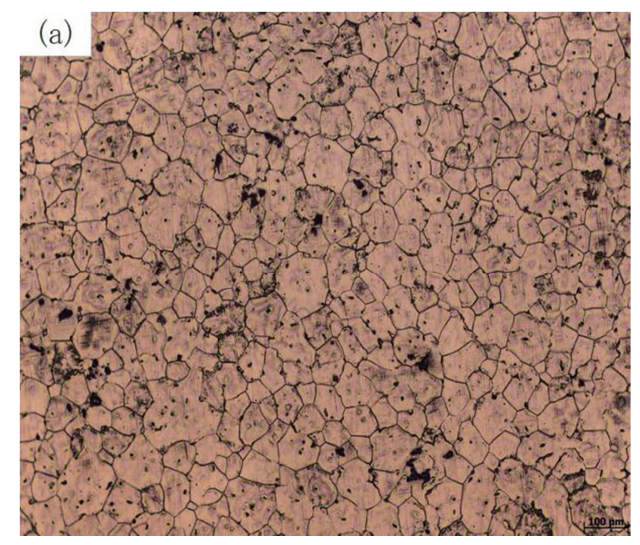

(a) $\mathrm{x}=0$ 


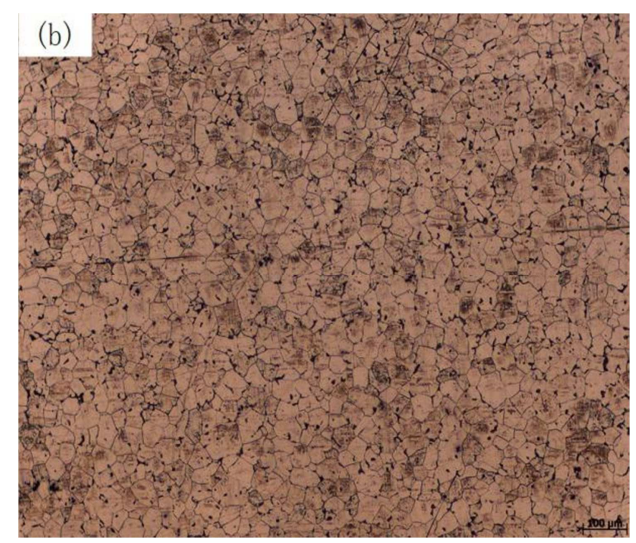

(b) $x=1$

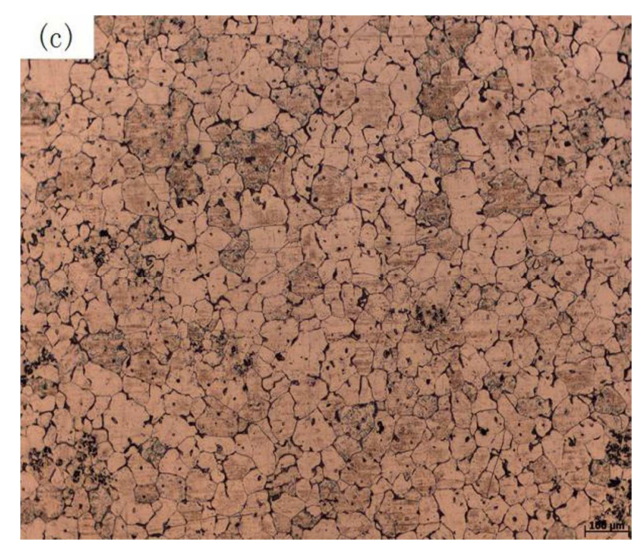

(c) $\mathrm{x}=3$

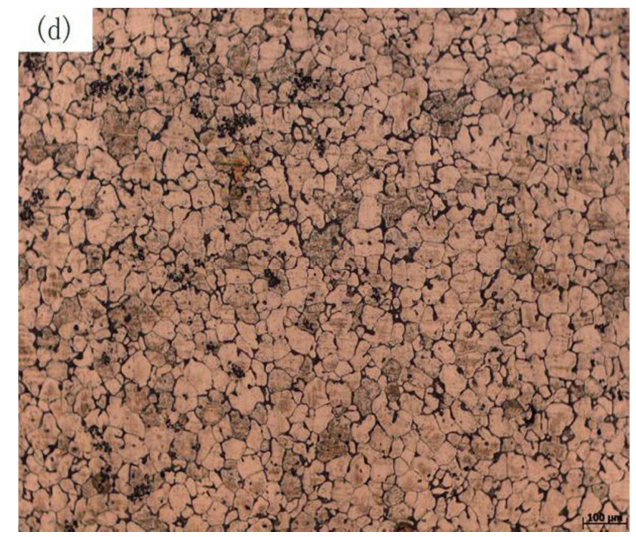

(d) $\mathrm{x}=5$.

Figure 2. Optical microstructures of as-cast Mg-5Y-2Nd-xSm-0.5Zr alloy.

Further X-ray diffraction analysis was performed on four as-cast alloys, as shown in Figure 3. According to the calibration of the map, the Mg-5Y-2Nd-0.5Zr alloy without $\mathrm{Sm}$ is mainly composed of $\alpha-\mathrm{Mg}, \mathrm{Mg}_{24} \mathrm{Y}_{5}$ and $\mathrm{Mg}_{41} \mathrm{Nd}_{5}$ phases. After $\mathrm{Sm}$ is added, a new $\mathrm{Mg}_{41} \mathrm{Sm}_{5}$ phase is formed in the alloy and the Sm content is increased with the addition of Sm. With the increase, the number of diffraction peaks of $\mathrm{Mg}_{41} \mathrm{Nd}_{5}$ and $\mathrm{Mg}_{41} \mathrm{Sm}_{5}$ phases increased, and the $\mathrm{Mg}_{24} \mathrm{Y}_{5}$ phase remained basically unchanged. This may be due to the fact that rare earth elements $\mathrm{Sm}$ and $\mathrm{Nd}$ have similar atomic radii and electronegativity is not much different, but $\mathrm{Sm}$ has a higher solid solubility than $\mathrm{Nd}$, and $\mathrm{Sm}$ atoms replace $\mathrm{Nd}$ atoms in part of $\alpha-\mathrm{Mg}$ matrix, with $\mathrm{Sm}$ The increase of the content of $\mathrm{Mg}_{41} \mathrm{Nd}_{5}$ and $\mathrm{Mg}_{41} \mathrm{Sm}_{5}$ phase increased.

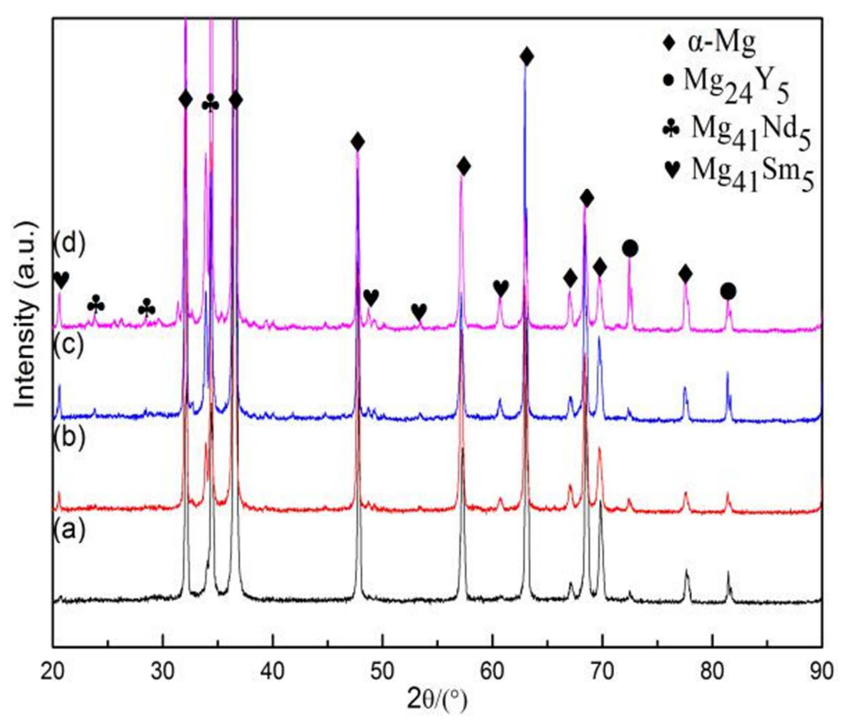

(a) $\mathrm{x}=0$; (b) $\mathrm{x}=1$; (c) $\mathrm{x}=3$; (d) $\mathrm{x}=5$

Figure 3. X-ray diffraction patterns of as-cast $\mathrm{Mg}-5 \mathrm{Y}-2 \mathrm{Nd}-\mathrm{xSm}-0.5 \mathrm{Zr}$ alloy.

\subsection{Mechanical Properties}

Table 2 and Figure 4 show the mechanical properties of the alloy samples subjected to standard tensile tests and hardness tests. According to the variation pattern of the graph in Figure 4 and the numerical results in Table 2, we can see that at room temperature, the tensile strength, yield strength, and hardness of the alloy appear to increase first and then decrease as the Sm content increases. The trend reached a maximum at a $\mathrm{Sm}$ content of $3 \%$, but the elongation decreased. Therefore, within the scope of this study, by adding 3\% Sm content to Mg-5Y-2Nd-0.5Zr alloy, the alloy has the best mechanical properties of tensile strength 245.9 $\mathrm{MPa}$, yield strength 207.6 $\mathrm{MPa}$, and elongation. The rate is $5.88 \%$ and the Vickers hardness value is HV85.9. This is mainly due to the greater solid solubility of the rare earth element $\mathrm{Sm}$ in magnesium alloys. With the increase of Sm content, the Sm elements dissolved in the alloy matrix are also increased. After $\mathrm{Sm}$ is dissolved in the matrix, it can be in the magnesium matrix. Causes strong lattice distortions, hinders the movement of dislocations, and strengthens the alloy [14-17]. In addition, the second phase of the alloy without $\mathrm{Sm}$ is mainly $\mathrm{Mg}_{24} \mathrm{Y}_{5}$ and $\mathrm{Mg}_{41} \mathrm{Nd}_{5}$ phases. Although the second phase is small and evenly distributed, the content is too small (as shown in Figure 2 (a)), and the strengthening effect is not obvious. With the addition of $\mathrm{Sm}$, on the one hand, the $\mathrm{Sm}$ atom can replace the $\mathrm{Nd}$ atoms in the solid solution and promote the formation of more $\mathrm{Mg} 41 \mathrm{Nd} 5$ phases in the alloy. On the other hand, it also increases a large number of new $\mathrm{Mg}_{41} \mathrm{Sm}_{5}$ phases. These $\mathrm{Mg}_{24} \mathrm{Y}_{5}$ and $\mathrm{Mg}_{41} \mathrm{Nd}_{5}$ phases in grain boundaries can effectively pin dislocations, hinder slip, and effectively improve the mechanical properties of the alloy [15-17]. However, when further increasing the Sm content to reach $5 \%$, due to the 
excessive number of second phases, a continuous network distribution on the grain boundary will form a severe splitting effect on the matrix, which will deteriorate the structure and reduce the strength and plasticity of the alloy. [18-21]. Therefore, Mg-5Y-2Nd-3Sm-0.5Zr alloy has the highest mechanical properties and the best overall performance.

Table 2. Mechanical properties of as-cast alloys at room temperature.

\begin{tabular}{|c|c|c|c|c|}
\hline Alloys & UTS/MPa & YS/MPa & EL/\% & HV \\
\hline $\mathrm{Mg}-5 \mathrm{Y}-2 \mathrm{Nd}-0.5 \mathrm{Zr}$ & 203.1 & 151.2 & 7.35 & 53.5 \\
\hline Mg-5Y-2Nd-1Sm-0.5Zr & 214.5 & 178.7 & 6.14 & 65.8 \\
\hline Mg-5Y-2Nd-3Sm-0.5Zr & 245.9 & 207.6 & 5.88 & 85.9 \\
\hline $\mathrm{Mg}-5 \mathrm{Y}-2 \mathrm{Nd}-5 \mathrm{Sm}-0.5 \mathrm{Zr}$ & 229.2 & 198.5 & 3.79 & 83.6 \\
\hline
\end{tabular}

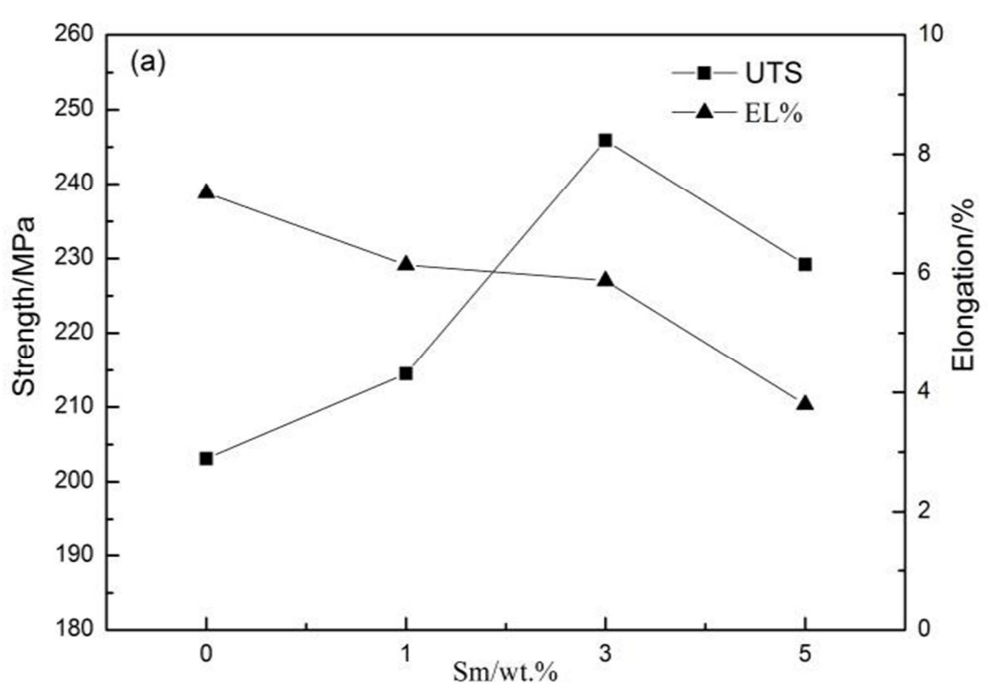

(a) Tensile properties

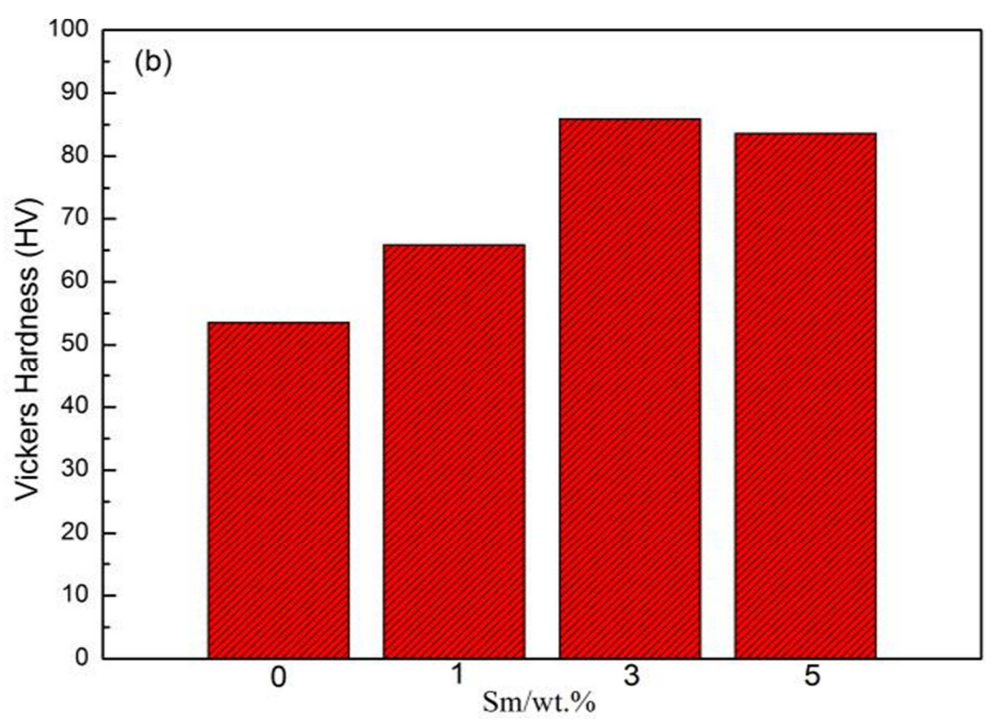

(b) Vickers Hardness

Figure 4. The variation diagram on mechanical properties of as-cast $\mathrm{Mg}-5 \mathrm{Y}-2 \mathrm{Nd}-\mathrm{xSm}-0.5 \mathrm{Zr}(\mathrm{x}=0,1,3,5)$ alloy.

\subsection{Fracture Behavior}

The fracture morphology of four cast alloys at room temperature is shown in Figure 5. It can be seen from the figure that the $\mathrm{Mg}-5 \mathrm{Y}-2 \mathrm{Nd}-0.5 \mathrm{Zr}$ alloy without $\mathrm{Sm}$ has the characteristics of mixed fractures of ductile fracture and local cleavage fracture. The fracture of the alloy is mainly composed of cleavage planes and torn edges. There are river patterns and small steps, and the torn edges are more developed (Figure 5 (a)). With the addition of $\mathrm{Sm}$ and increasing content, the morphology of the fracture changes significantly. When $\mathrm{Sm}$ is $1 \%$, the fracture becomes a mixed fracture composed of cleavage facets and torn edges, the dimples are significantly reduced, and the intergranular fracture characteristics (Figure 5 (b)), indicating that the grain boundary is the weak link of strength.. When $\mathrm{Sm}$ is $5 \%$, a small amount of cleavage facets can be observed in the 
fracture, and there is a significant increase in secondary cracks on the fracture. The intergranular fracture characteristics are obvious (Figure 5 (d)) due to the coarse second phase along the grain boundary. The intermittent network distribution not only does not play the role of strengthening the alloy, but on the contrary, the formation of large stress concentration at the grain boundary causes crack initiation and expansion, manifesting as obvious brittle fracture, thus reducing the strength and plasticity of the alloy simultaneously. In comparison, when the $\mathrm{Sm}$ is $3 \%$, the tear surface on the fracture surface is small and uniform, there is no obvious secondary crack and a large dissociation surface (Figure 5 (c)), which indicates that more energy is absorbed during the fracture process. Therefore, it shows high breaking strength and high elongation.

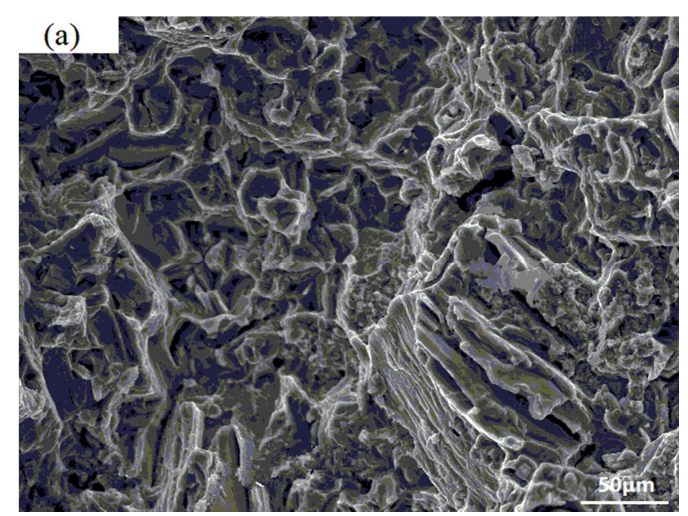

(a) $x=0$

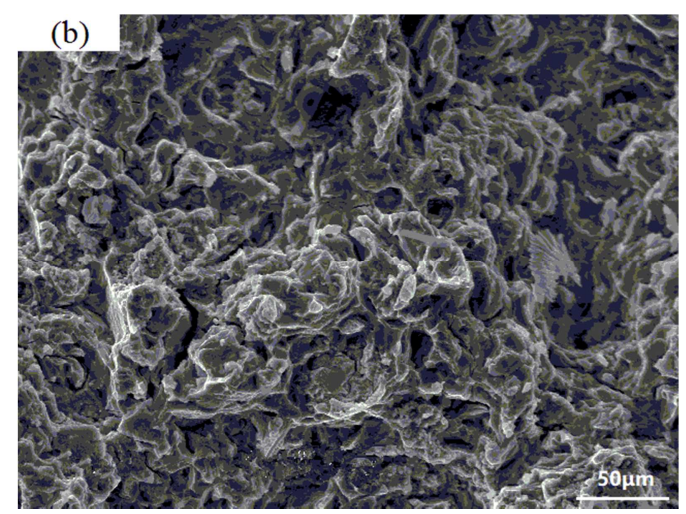

(b) $x=1$

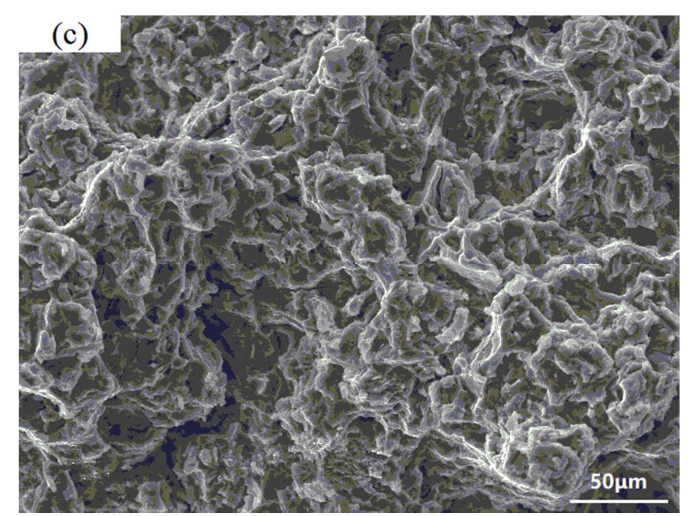

(c) $x=3$

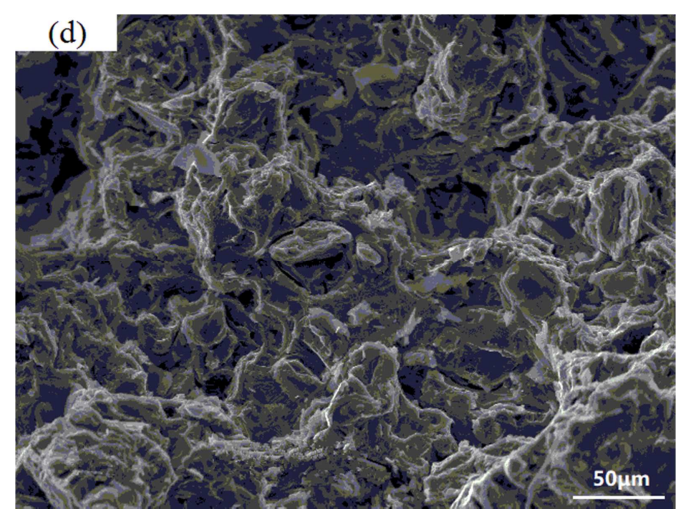

(d) $x=5$.

Figure 5. The tensile fracture SEM photographs of as-cast Mg-5Y-2Nd-xSm-0.5Zr alloy at $25^{\circ} \mathrm{C}$.

\section{Conclusion}

(1) The microstructure of $\mathrm{Mg}-5 \mathrm{Y}-2 \mathrm{Nd}-0.5 \mathrm{Zr}$ as-cast alloy is mainly composed of $\alpha-\mathrm{Mg}, \mathrm{Mg}_{24} \mathrm{Y}_{5}$ and $\mathrm{Mg}_{41} \mathrm{Nd}_{5}$ phases. With the addition of $\mathrm{Sm}$, the alloy grains are refined and the second phase $\mathrm{Mg}_{41} \mathrm{Sm}_{5}$ mainly distributed along the grain boundary is generated. The $\mathrm{Mg}_{41} \mathrm{Nd}_{5}$ phase inside the grains also increased slightly.

(2) With the addition of Sm, the tensile strength, yield strength and hardness of the as-cast alloys increase first and then decrease, and the elongation decreases. When $3 \%$ content of $\mathrm{Sm}$ is added, the alloy has the highest strength and hardness, high elongation, and the best comprehensive mechanical properties.

(3) The addition of appropriate amount of $\mathrm{Sm}$ can effectively improve the mechanical properties of Mg-5Y-2Nd-0.5Zr as-cast alloys. The strengthening method is mainly for the second phase strengthening, fine grain strengthening and solid solution strengthening also play a role.

\section{Acknowledgements}

This work was supported by the National Natural Science Foundation of China (Nos 51571084 and 51171059), and Henan Province Key Scientific and Technological Projects (Nos 152102210072).

\section{References}

[1] XIN Mingde, JI Zesheng. Research Situation and Application Prospects of Rare Earth in Foundry Magnesium Alloy [J]. Journal of the Chinese Society of Rare Earths, 2010, 28 (6): 643-653.

[2] WANG Mukong, SUN Jianxin, LIU Xinchao. Development of Research and Application of Cast Magnesium Alloys [J]. Nonferrous Metals, 2012, (2): 56-59.

[3] Robson J D, Haigh S J, Davis B. Grain Boundary Segregation of Rare-Earth Elements in Magnesium Alloys [J]. Metallurgical And Materials Transactions A-Physical Metallurgy And Material, 2016, 47A: 522-530. 
[4] Honghui Liu, Zhiliang Ning, Junying Yi, Qian Ma, Haichao Sun, Yongjiang Huang, Jianfei Sun. Effect of Dy addition on microstructure and mechanical properties of Mg-4Y-3Nd- $0.4 \mathrm{Zr}$ alloy [J]. Transactions of Nonferrous Metals Society of China, 2017, 4, 797-803.

[5] FU San-ling, LI Quan-an, JING Xiao-tian, et al. Effects of heat treatment on microstructure of

Mg-12Gd-2Y-0.5Sm- $0.5 \mathrm{Sb}-0.5 \mathrm{Zr}$ alloy [J]. Transactions of

Materials and Heat Treatment, 2014, 35 (4): 47-50.

[6] H. R. Jafari Nodooshan, Liu W C, Wu G H, Rao Y, Zhou C X, He S P, Ding W J, R. Mahmudi. Effect of Gd content on microstructure and mechanical properties of $\mathrm{Mg}-\mathrm{Gd}-\mathrm{Y}-\mathrm{Zr}$ alloys under peak-aged condition [J]. Materials Science \& Engineering A, 2014, 615 (2014): 79-86.

[7] Qiang Yang, Kai Guan, Xin Qiu, Deping Zhang, Shuhui Lv, Fanqiang $\mathrm{Bu}$, Yaqin Zhang, Xiaojuan Liu, Jian Meng. Structures of Al2Sm phase in a high-pressure die-cast $\mathrm{Mg}$ 4Al-4Sm-0.3Mn alloy [J]. Materials Science and Engineering: A, 2016, 675, 396-402.

[8] DING Wen-jiang, WU Yu-juan, PENG Li-ming, et al. Research and Application Development of Advanced Magnesium Alloys [J]. Materials China, 2010, 29 (8): 37-45.

[9] Serebryany V N, Rokhlin L L, Monina A N. Texture and anisotropy of mechanical properties of the magnesium alloy of Mg-Y-Gd-Zr system [J]. Inorganic Materials Applied Research, 2014, 5 (2): 116-123.

[10] Liping Zhong, Jian Peng, Song Sun, Yongjian Wang, Yun Lu, Fusheng Pan. Microstructure and Thermal Conductivity of As-Cast and As-Solutionized Mg-Rare Earth Binary Alloys [J] Journal of Materials Science \& Technology, 2017, 33, $1240-1248$.

[11] WU Wen-xiang, JIN Li, DONG Jie, et al. Research progress of high strength and heat resistant Mg-Gd-Y-Zr alloys [J]. The Chinese Journal of Nonferrous Metals, 2011, 21 (11): 2709-2718.
[12] FU San-ling, LI Quan-an, JING Xiao-tian, et al. Effect of Gd content on microstructure and mechanical properties of Mg-Gd-Sm-Zr alloy [J]. Transactions of Materials and Heat Treatment, 2016, 37 (8): 41-46.

[13] LI Quan-an, ZHANG Qing, WANG Yao-gui. Effects of Sm addition on microstructure and mechanical properties of a Mg-10Y alloy [J]. China Foundry, 2014, 11 (1): 28-32.

[14] Yang M B, Hou M D, Zhang J, et al. Effects of Ce, Y and Gd additions on as-cast microstructure and mechanical properties of Mg-3Sn-2Sr magnesium alloy. Transactions of Nonferrous Metals Society of China, 2014, 8: 2497-2506.

[15] Lapovok R, Zolotoyabko E, Berner A. Structure and mechanical property variations in $\mathrm{Mg}-\mathrm{Gd}-\mathrm{Y}-\mathrm{Zn}-\mathrm{Zr}$ alloy depending on its composition and processing condition [J]. Philosophical Magazine, 2016, 96: 1022-1046.

[16] LI Quan-an, LI Ke-jie, ZHANG Qing. Effects of Sm on microstructure and mechanical properties of aged Mg-12Gd-2Y-0.5Zr alloy [J]. Transactions of Materials and Heat Treatment, 2011, 32 (12): 84-88.

[17] TANG Yi-jin, ZHANG Zhen-yan, JIN Li, et al. Research progress on ageing precipitation of Mg-Gd alloys [J]. The Chinese Journal of Nonferrous Metals, 2014, 24 (1): 8-24.

[18] Kainer K U. Magnesium Alloys and Technology [M]. Weinheim: WILEY, 2003.

[19] Liu Ningyuan, Zhang Zhenyan, Peng Liming et al. Microstructure evolution and mechanical properties of Mg-Gd-Sm-Zr alloys. Materials Science and Engineering: A, 2015. 627: 223-229.

[20] Mordike B L, T Ebert. Magnesium: Properties-applications-potential [J]. Materials Science and Engineering: A, 2001, 302 (1): 37-45.

[21] Xiaoyang Xu, Xianhua Chen, Weiwei Du, Yuxiao Geng, Fusheng Pan. Effect of Nd on microstructure and mechanical properties of as-extruded $\mathrm{Mg}-\mathrm{Y}-\mathrm{Zr}-\mathrm{Nd}$ alloy [J]. Journal of Materials Science \& Technology, 2017, 33, 926-934. 